\title{
Effects of $\beta$-glucans on benign hyperplasia of prostate
}

Vetvicka Vaclav ${ }^{1 *}$, Richter Josef ${ }^{2}$, Kral Vlastimil' ${ }^{2}$, Pohorska Jitka² ${ }^{2}$ Stiborova Ivana ${ }^{2}$, Rajnohova Dobiasova Lucie ${ }^{2}$, Vincikova Andrea ${ }^{2}$ and Jilek Dalibor $^{2}$

${ }^{*}$ Correspondence: vaclav.vetvicka@louisville.edu

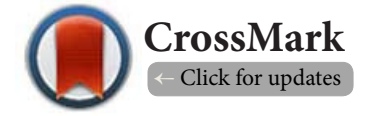

'Department of Pathology, University of Louisville, Louisville, KY, USA.

${ }^{2}$ Institute of Public Health in Ústí nad Labem, Czech Republic.

\begin{abstract}
Background: The stimulation of immune reactions represents a well-established effect of glucan. However, very little is known about the effects on prostate. In this report, we focused on patients with benign hyperplasia of prostate and evaluated the effects of glucan supplementation.

Methods: We measured the level of CRP, levels of total (tPSA) and free PSA (fPSA) and number of NK cells.

Results: We found positive effects on both NK cell numbers and on the PSA index, suggesting positive effects of glucan supplementation. Our data are further supported by a case report.

Conclusions: Our study offers preliminary results supporting the hypothesis that oral administration of glucan has positive effects in patients suffering from benign prostate hyperplasia. Our conclusion is supported by the case report showing significant effects with longer supplementation and higher dose.
\end{abstract}

Keywords: Glucan, supplement, prostate hyperplasia, NK cells, CRP, PSA

\section{Introduction}

Older patients often suffer from problems such as repeated fever, exhaustion and loss of physical endurance. These manifestations frequently result in diagnosis of nonspecific immunodeficiencies. In these patients, particularly in older men and patients over 50 years of age, as part of the complex clinical and laboratory evaluation, attention is focused on possible problems with LUTS (lower urinary tract symptoms). Prevalence of LUTS is increasing as much as the prevalence of benign prostatic hyperplasia [1]. LUTS often follows clinical manifestation of immunodeficits, which incidence increases with age. At our clinic, we have many patients with diagnosed benign prostatic hyperplasia (BPH), treated by alpha blockers (such as alfuzosin) as a treatment.

Included in our ongoing investigation of the b-glucan effects in patients with various immunodeficiencies, we evaluated the individual patients simultaneously diagnosed with $\mathrm{BPH}$ and with additional manifestation of immunodeficiencies, such as allergies or chronic pulmonary problems after supplementation of natural immunomodulator $\beta$-glucan.

$\beta$-Glucan is a well-established natural immunomodulator based on molecules of glucose connected by several types of linkages. The biological effects of $\beta$-glucan have been extensively studied and described. They range from stimulation of all facets of immunity, including anti-infectious immunity, to potentiation of cancer defense, and from stress reduction to reduction of cholesterol (for review see $[2,3]$ ). The palliative effects of oral administration of yeast-derived $\beta$-glucan were recently demonstrated in clinical trials evaluating children with chronic respiratory problems $[4,5]$.

\section{Materials and methods \\ Patients and methods}

A randomized, double-blind, placebo-controlled trial compared $\beta$-glucan \#300 and placebo in in men with benign prostatic hyperpalsia and lower urinary tract symptoms (LUTS). Our group consisted of 16 patients. Seven were supplemented with glucan (average age $63.4 \pm 11.8$ ), and 9 with placebo (average age $66.7 \pm 11.8$ ). The study was approved by the Ethics committee of the Public Health Institute. This study was performed in agreement with Helsinki declaration (revised version 2000.09.01) and in full agreement with rules for clinical testing for the Czech Republic. All patients were fully informed about the conditions of the study and were in agreement. Glucan was given similarly to our previous studies. It consisted of two pills ( $200 \mathrm{mg}$ total) one hour after a meal for a 2 month period $[5,6]$.

At the beginning of the study, we obtained samples for immunological tests. We measured the levels of C-reactive protein 
Vaclav et al. Pathology Discovery 2014,

http://www.hoajonline.com/journals/pdf/2052-7896-2-8.pdf

(CRP) in serum using nephelometer Siemens BNM II as suggested by the manufacturer. Levels of total (tPSA) and free (fPSA) PSA were measured by a two step chemiluminiscent immunoanalysis on microparticles (CMIA) using and ARCHITECT System (Abbott, Ireland). For evaluation of cellular immunity, we measured the levels of NK cells. The relative percentage of NK cells (shown as \% of total lymphocyte population) was determined by using a flow cytometer FACSCalibur by a double staining of $\mathrm{CD} 3^{-} \mathrm{CD} 16^{+} \mathrm{CD} 56^{+}$population. The absolute amount of these cells (given as number of cells/ $\mathrm{ml}$ ) was calculated from the total number of leucocytes and differential counts. Evaluation of the prostate disease was done using the form for the international score of prostatic syndromes (IPSS) as described before [7]. Identical tests were done at the conclusion of the study.

\section{Glucan}

Yeast-derived insoluble Glucan \#300 were purchased from Transfer Point (Columbia, SC). This glucan is over $85 \%$ pure.

\section{Statistical analysis}

Statistical significance was evaluated by a pair t-test using a GraphPad Prism 502 software (GraphPad Software, USA).

\section{Case report}

A 79 years old patient, diagnosed with immune dysfunction after surgery due to bronchogenic tumor of right lung lobe, actually suffering from respiratory problems without allergic symptoms. In 2010, he was tested for urinary problems with a final diagnosis of benign prostatic hyperplasia. The actual IPSS score of 16 lead to the clinical evaluation with findings of fPSA/tPSA index of 18, higher CRP level (3.2 mg/L) and subnormal level of NK cells ( 265 cells $/ \mathrm{ml})$. The final clinical manifestations of urogenital tract problems were solved by 14 days of antibiotic treatment (Gyrablock 400; Norfloxacinum Medochemie). After the start of treatment with alpha blockers (Alfuzosin Merck 10 mg; Genetics, UK), stabilization of clinical symptoms occurred without any signs of disease progression. Since 2012, supplementation of $200 \mathrm{mg} /$ day glucan was added; in 2013 the dose was increased to $400 \mathrm{mg} /$ day. The result was significant improvement of clinical symptoms, reduction of inflammatory irritation, significant decrease of IPSS score to 12 , and a strong increase of NK cell level. Increase of PSA index to 32 was observed. In addition, the general condition of the clinical manifestation of respiratory problems improved.

\section{Results}

At the beginning of the study, the levels of CRP in the glucan supplemented study (G1) were $4.21 \pm 2.11 \mathrm{mg} / \mathrm{L}$ and $3.76 \pm 1.66 \mathrm{mg} / \mathrm{L}$ in the placebo group (P1), thus making the initial differences statistically insignificant. At the end of the treatment, the glucan-supplemented group (G2) showed a strong decrease of CRP levels (Figure 1), which almost reached significance $(p=0.051)$. Placebo group (P2) showed a small

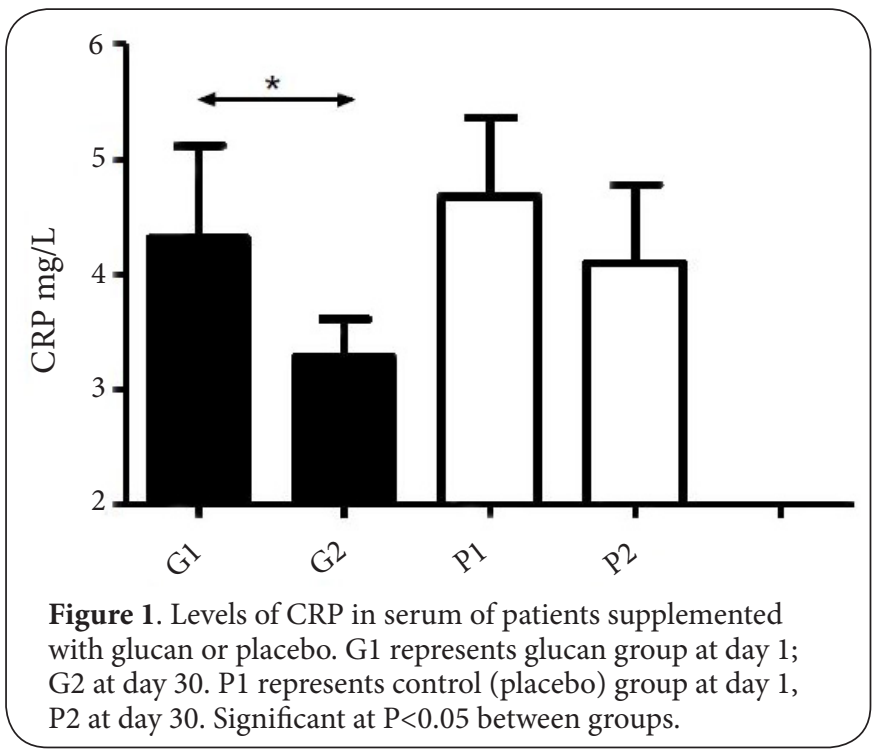

increase of CRP levels ( $p=0.221)$.

Figure 2 summarized our findings of the changes in NK cell levels. There were no initial differences between groups G1 and $P 1$, but we found a significant increase in number of NK cells from 196 to 260 ( $p=0.023$ ) in $\mathrm{G} 1$ group. The changes in the placebo group P2 are not significant (from 225 cells to 215 cells). Similar dynamics can be seen at the values of PSA index (Figure 3). The supplemented group showed a significant increase in the index from 28.8 to $35.3(p=0.036)$, whereas changes in the placebo group were negligible (from 28.6 to 26.7). Figure 4 summarizes the changes in CRP levels, number of NK cells and fPSA/tPSA index in patient with long-term supplementation with glucan.

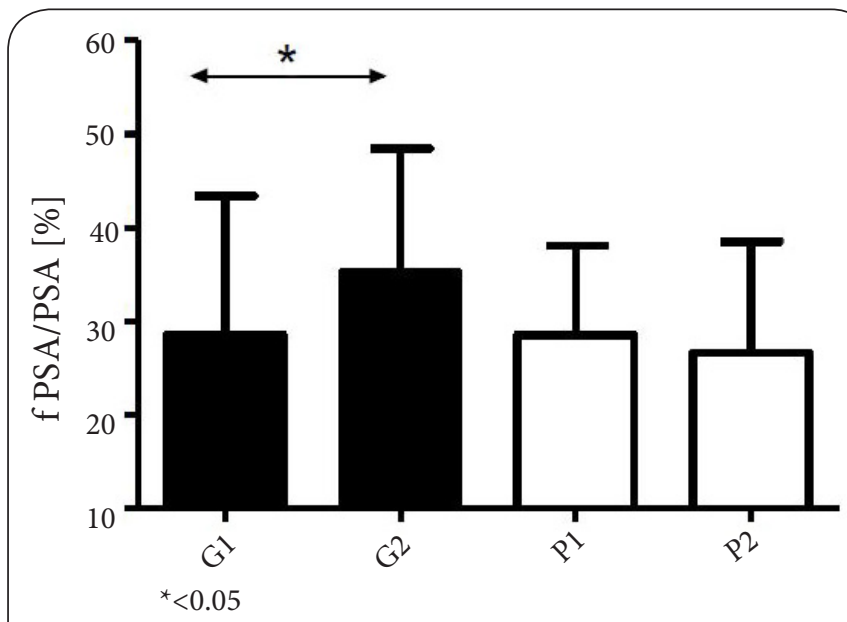

Figure 2. Effects of glucan supplementation on number of NK cells. Significant at $\mathrm{P}<0.05$ between groups.

\section{Discussion and conclusion}

Benign hyperplasia of prostate is one of the most common diseases in older men. With the aging population in developed 


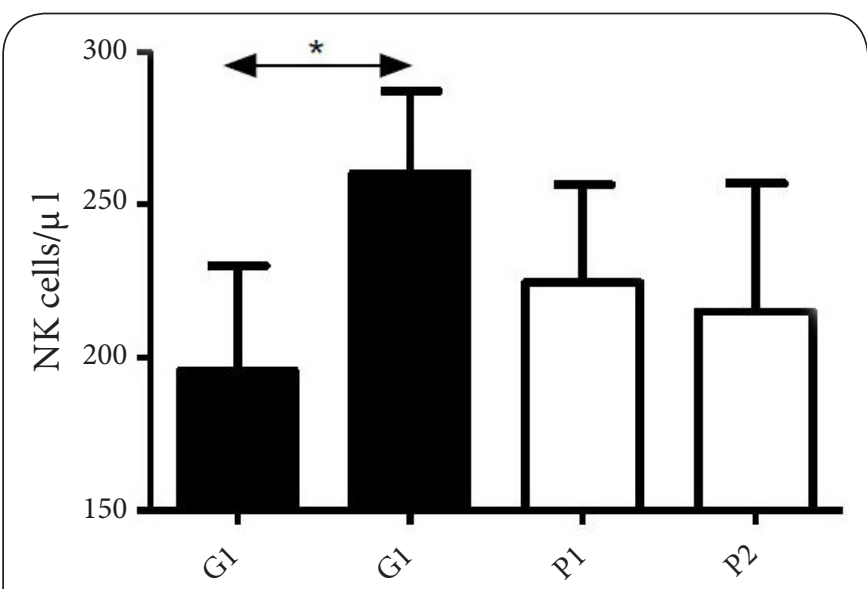

Figure 3. Effects of glucan supplementation on PSA index. Significant at $\mathrm{P}<0.05$ between groups.

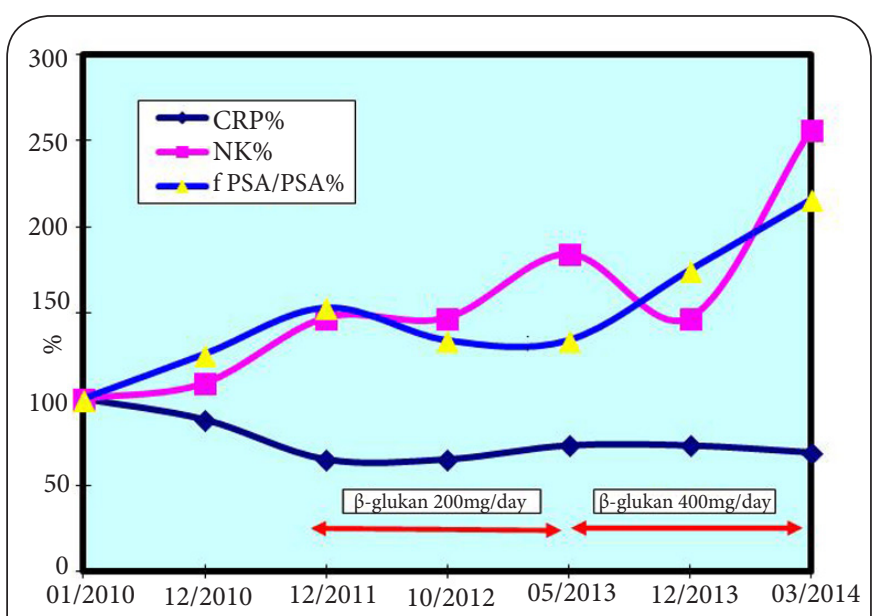

Figure 4. Changes in CRP levels, number of NK cells and fPSA/tPSA index in patient with long-term supplementation with glucan. Initial values were recalculated as $100 \%$.

countries, a significant increase in the incidence of this disease is expected [8]. Therefore, new approaches are seeking to enable an increase in the precision of diagnostics, and to better monitor the disease and/or the patient and are being sought. Several papers demonstrated the possibility that cancer stem cells (CSCs) can be recognized in vitro and destroyed by cytotoxic T lymphocytes, NK cells and by $g$ d T lymphocytes [9]. The administration of glucans, known for significant positive effects in patients with cancer undergoing chemotherapy, where they support hematopoiesis [10], might also play a positive role in these cases. Wenner et al., used polysaccharidic extract of a Tramettes versicolor mushroom and in a murine model found immunostimulating and tumor suppressing activities, which were further potentiated by docetaxel administration [11]. Studies of Lemieszek and Rzeski testing anticancer effects of polysaccharides isolated from Basidiomycetes concluded that most of anticancer polysaccharides belong to $1(1-3),(1-6)-\beta$-glucans or (1-3)-a-glucans [12]. Readers seeking a recent review of the anticancer effects of glucan should read the recent monograph [3]. An additional summary of the immunomodulatory effects of glucans, both in experimental and clinical conditions, can be found in $[2,13]$. The biological effects of glucans are thought to depend on molecular weight, solubility, branching or tercial structure. However, the direct comparison between physicochemical characteristics of glucans and their biological and immunological properties was never fully determined.

Yet, despite the ever increasing range of glucan effects -reaching from antiinfectious immunity to reduction of stress or cholesterol levels-the results of glucan in patients suffering from lower urinary tract syndromes were never described. Our hypothesis was based on findings of Wenner et al., who showed some effects of glucan in mouse model of human prostate cancer [11]. This group found that glucan administration increased suppression of tumor growth, apoptosis and antitumor response. Similar observations were found by others $[14,15]$. In different types of cancer, treatment with glucan and melatonin (individually or together) inhibited progression of adenocarcinoma [16]. A water extract of Phellius linteus had positive effects in benign prostate hyperplasia [8].

Glucans stimulate both nonspecific and specific immunity. Based on our clinical trials confirming effects on CRP, lysozyme and immunoglobulins in children with respiratory problems [4-6], we decided to measure the effects of glucan on CRC and NK cell levels in patients with benign prostate hyperplasia. The effects of CRP levels were interesting, but just at the borders of statistical significance. Chronic inflammation was found to be present in LUTS and, depending on treatment, the level of CRP can decrease [7]. The less pronounced decrease of CRP levels in our patients can be caused by shorter application of glucan, by lower than optimal dose or by a relatively low number of studied individuals low CRP levels at the start of study. On the other hand, significant improvement of NK cell numbers is in agreement with studies evaluating NK cells in clinical application. Sotosek et al., showed that a decrease of NK cell number in benign hyperplasia of prostate can be the result of both progression of the disease, including prostate cancer [17]. The authors hypothesize that NKT and Tregs may play the leading role in immunopathogenesis of this disease. To better study the effects of glucan supplementation, we also measured PSA index. Our findings of strong increase of PSA index are important, particularly when accompanied with improvements of IPSS score.

Model experiments suggested that glucan has, via activation of several immune mechanisms, palliative effects on various tumors (for review see [18]). When glucan is used simultaneously with medication, its effects are potentiated [11]. Our study offers, mostly due to the relatively low number of patients, only preliminary results supporting the hypothesis that oral administration of glucan has positive effects in patients suffering from benign prostate hyperplasia. However, our conclusion is supported by the case report showing significant 
Vaclav et al. Pathology Discovery 2014,

http://www.hoajonline.com/journals/pdf/2052-7896-2-8.pdf

doi: $10.7243 / 2052-7896-2-8$

effects with longer supplementation and higher dose.

List of abbreviations

LUTS: Lower urinary tract symptoms

tPSA: total PSA

fPSA: free PSA

PSA: Prostate specific antigen

NK: Natural killer

BPH: Prostatic hyperplasia

CRP: C-reactive protein

IPSS: International score of prostatic syndromes

CSCs: Cancer stem cells

\section{Competing interests}

The authors declare that they have no competing interests.

Authors' contributions

\begin{tabular}{|l|c|c|c|c|c|c|c|c|}
\hline Authors' contributions & VV & RJ & KV & PJ & SI & RDL & VA & JD \\
\hline Research concept and design & $\checkmark$ & $\checkmark$ & $\checkmark$ & -- & -- & -- & -- & -- \\
\hline Collection and/or assembly of data & -- & $\checkmark$ & -- & $\checkmark$ & $\checkmark$ & $\checkmark$ & $\checkmark$ & $\checkmark$ \\
\hline Data analysis and interpretation & $\checkmark$ & $\checkmark$ & -- & $\checkmark$ & $\checkmark$ & $\checkmark$ & $\checkmark$ & $\checkmark$ \\
\hline Writing the article & $\checkmark$ & $\checkmark$ & $\checkmark$ & -- & -- & -- & -- & -- \\
\hline Critical revision of the article & $\checkmark$ & $\checkmark$ & $\checkmark$ & $\checkmark$ & $\checkmark$ & $\checkmark$ & $\checkmark$ & $\checkmark$ \\
\hline Final approval of article & $\checkmark$ & $\checkmark$ & $\checkmark$ & $\checkmark$ & $\checkmark$ & $\checkmark$ & $\checkmark$ & $\checkmark$ \\
\hline Statistical analysis & -- & -- & -- & -- & -- & $\checkmark$ & -- & -- \\
\hline
\end{tabular}

Acknowledgement and funding

This study was supported by the Technology Agency of the Czech Republic TACR TA 0202094.

Publication history

Editor: Bin Guan, Johns Hopkins Medical Institutions, USA.

Senior Editor: Takuji Tanaka, Gifu University, Japan.

EIC: Markus H. Frank, Harvard Medical School, USA.

Received: 21-May-2014 Final Revised: 26-Aug-2014

Accepted: 14-Oct-2014 Published: 21-Oct-2014

\section{References}

1. Jiang $\mathrm{YH}$, Liao $\mathrm{CH}$ and Kuo $\mathrm{HC}$. How much improvement is needed for a real difference of lower urinary tract symptoms after long-term combination therapy for benign prostatic hyperplasia. Int $J$ Clin Pract. 2014; 68:1081-6. | Article | PubMed

2. Vetvicka $V$ and Novak M. Biology and Chemistry of Beta Glucan. Volume 2. Beta-glucan, Structure, Chemistry and Specific Application. Bentham Science Publishers. 2013.

3. Vetvicka V. $\boldsymbol{\beta}$-Glucans as Natural Biological Response Modifiers. Nova Science Publishers, New York, 2014. | Book

4. Vetvicka V, Richter J, Svozil V, Rajnohova Dobiasova L and Kral V. Placebodriven clinical trials of Transfer Point Glucan \#300 in children with chronic respiratory problems: Antibody production. Am. J. Immunol. 2013; 9:43-47. | Article

5. Richter J, Svozil V, Kral v, Rajnohova Dobiasova L, Stiborova I and Vetvicka $V$. Clinical trials of yeast-derived $\beta$ - $(1,3)$ glucan in children: effects on innate immunity. Ann. Transl. Med. 2014; 2. | Article

6. Vetvicka V, Richter J, Svozil V, Rajnohova Dobiasova L and Kral V. Placebodriven clinical trials of Transfer Point Glucan \#300 in children with chronic respiratory problems: III. Clinical findings. Am. J. Immunol. 2013; 9:88-93. | Pdf

7. Hung S-F, Chung S-D and Kuo H-C. Increased serum C-reactive protein level is associated with increased storage lower urinary tract symptoms in men with benign prostatic hyperplasia. PLOS One. 2014; 9.| Article

8. Kim YN, Kim MS, Chun SS and Choi JH. Effect of Phellius linteus water extract on benign prostatic hyperplasia. Nutr Res Pract. 2013; 7:172-7. | Article | PubMed Abstract | PubMed Full Text

9. Jachetti E, Mazzoleni S, Grioni M, Ricupito A, Brambillasca C, Generoso L, Calcinotto A, Freschi M, Mondino A, Galli R and Bellone M. Prostate cancer stem cells are targets of both innate and adaptive immunity and elicit tumor-specific immune responses. Oncoimmunology. 2013; 2:e24520. | Article | PubMed Abstract | PubMed Full Text

10. Weitberg $A B$. A phase $1 / I I$ trial of beta- $(1,3) /(1,6) \mathrm{D}$-glucan in the treatment of patients with advanced malignancies receiving chemotherapy. J Exp Clin Cancer Res. 2008; 27:40. | Article | PubMed Abstract | PubMed Full Text

11. Wenner CA, Martzen MR, Lu H, Verneris MR, Wang $H$ and Slaton JW. Polysaccharide-K augments docetaxel-induced tumor suppression and antitumor immune response in an immunocompetent murine model of human prostate cancer. Int J Oncol. 2012; 40:905-13. | Article | PubMed Abstract | PubMed Full Text

12. Lemieszek $M$ and Rzeski W. Anticancer properties of polysaccharides isolated from fungi of the Basidiomycetes class. Contemp Oncol (Pozn). 2012; 16:285-9. | PubMed Abstract | PubMed Full Text

13. Ramberg JE, Nelson ED and Sinnott RA. Immunomodulatory dietary polysaccharides: a systematic review of the literature. Nutr J. 2010; 9:54. | Article | PubMed Abstract | PubMed Full Text

14. Fullerton SA, Samadi AA, Tortorelis DG, Choudhury MS, Mallouh C, Tazaki $\mathrm{H}$ and Konno $\mathrm{S}$. Induction of apoptosis in human prostatic cancer cells with beta-glucan (Maitake mushroom polysaccharide). Mol Urol. 2000; 4:7-13. | PubMed

15. Finkelstein MP, Aynehchi S, Samadi AA, Drinis S, Choudhury MS, Tazaki H and Konno $S$. Chemosensitization of carmustine with maitake betaglucan on androgen-independent prostatic cancer cells: involvement of glyoxalase I. J Altern Complement Med. 2002; 8:573-80. | Article

16. Kabasakal L, Sener G, Balkan J, Dogru-Abbasoglu S, Keyer-Uysal M and Uysal M. Melatonin and beta-glucan alone or in combination inhibit the growth of dunning prostatic adenocarcinoma. Oncol Res. 2011; 19:25963. | Article | PubMed

17. Sotosek S, Sotosek Tokmadzic V, Mrakovcic-Sutic I, Tomas MI, Dominovic M, Tulic V, Sutic I, Maricic A, Sokolic J and Sustic A. Comparative study of frequency of different lymphocytes subpopulation in peripheral blood of patients with prostate cancer and benign prostatic hyperplasia. Wien Klin Wochenschr. 2011; 123:718-25. | Article | PubMed

18. Vannucci L, Krizan J, Sima P, Stakheev D, Caja F, Rajsiglova L, Horak V and Saieh M. Immunostimulatory properties and antitumor activities of glucans (Review). Int J Oncol. 2013; 43:357-64. | Article | PubMed Abstract $\mid$ PubMed Full Text

\section{Citation:}

Vaclav V, Josef R, Vlastimil K, Jitka P, Ivana S, Lucie RD, Andrea $V$ and Dalibor J. Effects of $\beta$-glucans on benign hyperplasia of prostate. Pathol Discov. 2014; 2:8. http://dx.doi.org/10.7243/2052-7896-2-8 